\title{
Историографический акцент русской
}

\section{литературы}

\author{
Ольга Вячеславовна Червинская (Черновцы)
}

\begin{abstract}
Аннотация
Рассматривается одна из важнейших функций литературы, связанная с сохранением исторической памяти культуры. Порожденные «малым» историческим временем, произведения пребывают и осуществляются в «большом» (по М. Бахтину), чем и определяется их историографический ресурс. Этот компонент предполагает присутствие в художественном тексте каких-либо конкретных для данной эпохи знаковых фактов, он вскрывает мотивацию исторических событий, их допустимую интерпретацию (фиксирует состояние, предшествующее энтропии уклада, исторический консерватизм, национальные версии либерализма и пр.). В качестве культурологического истока взято «Слово о законе и благодати» митрополита Иллариона, преемственность акцентной идеи которого сохраняется и в русской классике. Тема раскрывается на примере наследия Ф. Достоевского.
\end{abstract}

\section{Ключевые слова}

историограсизм художественной словесности; культурологический исток; «апперцептивный фон» литературы; акцентная идея; «Слово о законе и благодати»; Ф. Достоевский

\section{Abstract \\ Historiographic Accent of Russian Literature}

The given article considers one of the major functions of the literature, connected with conservation of historical memory of culture. The works generated by a "small" historical time, remain and are carried out in a "big" time (by M. Bakhtin), which defines their historiographic resource. This component assumes a presence in the art text some specific facts, indicative for the given epoch, opens the motivation of historical events, their admissible interpretation (locates a condition previous to the entropy of the way, historical conservatism, national versions of liberalism etc.). As a culturological source was taken the Sermon on Law and Grace by Metropolitan Hilarion, the continuity its accentuated idea is kept in Russian classics. The subject develops on the example F. Dostoevsky's heritage.

\section{Key words}

historiography of the literature; culturological source; "apperceptive background" of literature; accentuated idea; Sermon on Law and Grace; F. Dostoevsky 
По существу литература, эта художественная фикция действительности, оказывается ничем иным, как производным текущей истории, хотя подспудная связь между исторической действительностью и аргументированными ею эстетичными формами не во всех случаях достаточно очевидна, чтобы признать ее закономерной. Любые художественные фикции порождены «малым» историческим временем, пребывающем в «Большом», на чем настаивал М. Бахтин. К этому временному стыку они и адаптируют свое собственное состояние. Существует, по определению этого ученого, «язык дня», существуют, как он пишет, «даже язъки дней: ведъ и сегодняшний и вчерашний сочиально-идеологчческий и политический день в известном смысле не имеют общего языка; у каждого дня своя сочиально-идеологическая, смысловая конъюнктура, свой словарь, своя акцентная система, свой лозунг, своя бранъ и своя похвала» ${ }^{1}$. Историографический компонент в литературе не предполагает одно лишь присутствие в тексте каких-либо конкретных для данной эпохи знаковых фактов. Он, что важнее, раскрывает мотивацию не только самих исторических событий, но и их допустимую интерпретацию: например, фиксирует состояние, предшествующее энтропии уклада, исторический консерватизм или ревизионизм.

В максимально напряженные моменты исторической реальности писатель, фактически, так или иначе делается историографом, о чем свидетельствует весь опыт мировой литературы. Однако и в более спокойные времена историография в латентном виде присутствует в его текстах. Славянским литературам, в том числе - русской, есть что прояснить для себя и для других в этом вопросе.

Художественное освещение истории и историческая наука ныне автономны. Однако современные историки и сегодня не считают предосудительным сослаться на мнение литературного классика, особенно на уровне концептуальных высказываний, признавая, что в некоторых случаях «историкам только и остается, ито подглядывать за кулисы, где иронично посмеивается Клио» ${ }^{2}$. Конверсия художественного восприятия действительности в достоверный, а, следовательно, исторический факт - не менее любопытный ракурс, чем, напротив, вопрос о том, как исторический факт порождает художественное обобщение.

На сегодняшний день существует твердая традиция вести литературный вектор русской культуры от Ярославовой «Русской правды» (1016 или 1030 гг.), «Повести временных лет» (3-я редакция - 1117 р.), летописей, а также «Слова о полку Игореве» (после 1185 г.). Сюда же включают найденное в ХІХ ст., затем утерянное, затем, уже в ХХ ст., вновь обнаруженное «Слово о погибели Рускыя земли и по смерти великого князя Ярослава» (датируемое XIII веком), которое в свое время получило широкое обсуждение в науке. История вопроса его толкований, датировок и художественной оценки была собрана и прокомментирована историком Антоном Горским в самых лучших традициях герменевтического дискур-

1 BAHTIN, M. M.: Voprosy literatury i jestetiki: Issledovanija raznyh let. Moskva: Hudozhestvennaja literatura, 1975, s. 104.

2 FISANOV, V. P.: Prohrane supernyctvo (SŠA ta Avstro-Uhorščyna u Central'nijJevropi v roky Peršoji svitovoji vijny). Černivci: Zoloti lytavry, 1999, s. 217. 
$\mathrm{ca}^{3}$, ныне оно включено в канонический круг древнерусских текстов ${ }^{4}$. Исследователь-историк не мог не подчеркнуть имевшую место в те времена условность датировок событий, первозначимость общей идеи, сложность прочтения самого текста (например, как определить в нем конец той или иной фразы, правильное место пунктуационного знака и т. п. ${ }^{5}$ ).

Ключевой акцент содержится в следующем выводе: «Галичко-Волынская летопись (к которой относится часть Ипатьевского свода, содержашая рассматриваемые известия) представляет собой повествование, в котором первоначально не было погодной сетки; проведенная позднее (составителем Ипатьевского списка начала XV в.) разбивка на даты во многом условна; летописчъ по ходу изложения затрагивали как более ранние, так и позднейшие события» ${ }^{6}$. Сравнение трех летописей убеждало, что описания исторических событий, различных междоусобиц могли перекочевывать из одного текста в другой на протяжении не одного столетия, получая соответствующую интерпретацию (версию) переписчика, что и делало датировку исторических событий достаточно условной.

«Особую версию событий, - подчеркивает исследователь, - встречаем в украинской Густынской летописи (первая половина ХVII в.)»: “Сравнение текста Густынской летописи за 1235-1236 г2. с более ранними летописями показывает, что в ней соединен текст Ипатъевской летописи (сокращенный) с текстом пространного варианта «новгородской» версии, оченъ близким к тексту, иитаемому в Тверском сборнике» ${ }^{7}$. Таковой была историографическая практика в те времена. И тем не менее, все перечисленные выше раритеты имеют неоспоримую ценность как исторические и одновременно художественные памятники, как культурологический исток всей русской словесности.

Главным для нас в этой работе является вывод автора, основанный на начатом и обстоятельно осуществленном еще А. В. Соловьевым ${ }^{8}$ сопоставлении данного «Слова» со «Словом о полку Игореве». Узловой акцент ставится на жанровой близости: «...оба они (и только они из сохранившихся произведений русской литературы домонгольского периода) сочетают в себе черты эпоса, лирики и публичистики. Очень вероятно, что автор “Слова о погибели» бъл знаком со “Словом о полку Игореве», хотя отсутствие прямых текстуальных заимствований не позволяет утверждать это категорически. Три списка, обнаруженных в новое время - один “Слова о полку Игоре-

3 GORSKIJ, A. A.: Problemy izuchenija «Slova o pogibeli Ruskyja zemli» (K 750-letiju so vremeni napisanija). Trudy Otdela drevnerusskoj literatury 43, 1990, s. 18.

4 Slovo o pogibeli Russkoj zemli. Moskva: Nauka, 2005.

5 GORSKIJ, A. A.: Problemy izuchenija «Slova o pogibeli Ruskyja zemli» (K 750-letiju so vremeni napisanija). Trudy Otdela drevnerusskoj literatury 43, 1990, s. 35.

6 GORSKIJ, A. A.: Problemy izuchenija «Slova o pogibeli Ruskyja zemli» (K 750-letiju so vremeni napisanija). Trudy Otdela drevnerusskoj literatury 43, 1990, s. 26.

7 GORSKIJ, A. A.: Problemy izuchenija «Slova o pogibeli Ruskyja zemli» (K 750-letiju so vremeni napisanija). Trudy Otdela drevnerusskoj literatury 43, 1990, s. 28.

8 SOLOV'EV, A. V.: Zametki $k$ «Slovu o pogibeli Ruskyja zemli». Trudy Otdela drevnerusskoj literatury 15, 1958, s. 82 . 
ве» и два «Слова о погибели Рускъя земли», - составляют то драгоченное наследие, которое дошло от светской лиро-эпической публичистической литературы Руси ХII-ХIII вв.» ${ }^{9}$. Таким образом, вне вопроса о возможном заимствовании, наше внимание привлекает собственно это конкретное определение - светская лиро-эпическая публицистика. Оно указует на тот самый зародыш с его корневищами, ту исходную «генетическую доминанту», которая, возможно, и определяет имманентный русский стиль при любых, в дальнейшем дополняющих его творческих креативах. Оставим в стороне вопрос о том, в каком ключе могла эксплуатироваться лиро-эпическая тематика этих образцов в последующие времена (из последних примеров - одноименная «Слову о погибели» филиппика Дмитрия Нечаенко, непосредственно связанная с постсоветской эпохой времен Бориса Ельцина $\left.{ }^{10}\right)$. Но не только в этом вопрос.

Следует обратить внимание на более важный момент: наличие и своеобразие так называемого «апперцептивного фона» русской литературы. Вероятнее всего, его надлежало бы связать с полным корпусом имеющихся текстов древнерусской письменности, но в качестве одного примера интересно взять наследие упоминаемого в Лаврентьевской летописи Илариона Киевского (Русина) ${ }^{11}$ - первого из русских митрополитов эпохи Ярослава Мудрого (ум. после 1051 г.), которому приписывается авторство первого русского литературно-философского сочинения «Слово о Законе и Благодати» (датируется по-разному: от 1037 до 1051 гг. $)^{12}$. Этот памятник письменности, при имеющих место научных дискуссиях относительно его мотивации и провозглашения ${ }^{13}$, в основном принято определять как жанр торжественной речи ${ }^{14}$, хотя, по сути, мы имеем дело с концептом.

В полном соответствии с христианской идеей Евангелия «Слово» открывается провозглашением «истины» как первенства «благодати»над «законом», чего на тот момент требовала, как известно, сложившаяся ситуация в Киевской митрополии - наглядный пример историографической подоплеки создания Иларионова текста: «О законе, данном через Моисея, и о благодати и истине, явленной Иисусом Христом, и о том, как закон миновал, а благодать и истина наполнила всю землю и вера распространилась во всех народах вплоть до нашего народа русского; и похвала великому князю нашему Владимиру, которым мы были крешены; и молитва $\kappa$ Богу от всей земли нашей».

В нашем аспекте созвучным является вывод С. Я. Сендеровича об этом произведении как экзегетическом тексте с четко выраженной «смысловой конфигура-

9 GORSKIJ, A. A.: Problemy izuchenija «Slova o pogibeli Ruskyja zemli» (K 750-letiju so vremeni napisanija). Trudy Otdela drevnerusskoj literatury 43, 1990, s. 38.

10 См.: http://www.stihi.ru/2011/06/08/2938

11 Lavrent'evskaja letopis'. Moskva: Izd-vo AN SSSR, 1962, stlb. 155-156.

12 MOLDOVAN, A. M.: «Slovo o zakone i blagodati»Ilariona. Kiev: Naukova dumka, 1984.

13 UZHANKOV, A. N.: «Slovo o Zakone i Blagodati» $i$ drugie tvorenija mitropolita Ilariona Kievskogo. Moskva: Akademika, 2013, s. 49-73.

14 MOLDOVAN, A. M.: «Slovo o zakone i blagodati» Ilariona. Kiev: Naukova dumka, 1984, s. 7. 
иией», позволяющей «увидеть единство трех планов истории, к которым обрашается Иларион. Рождение Израиля, рождение христианства и рождение нового христианского народа, Руси, - все три исторические драмз происходят на основе одной и той же парадигмъ - в качестве триумфа младшей отрасли над старшей» ${ }^{15}$. Вопреки оппонентам ученого, нельзя не согласиться с мнением, что этим текстом «заложена историософская основа, на которой можно строить русскую историографию как продолжение священной истории. Эта основа, - подчеркивается, - в полной мере будет использована в «Повести временных лет» для решения очень трудных политических проблем с точки зрения провиденииального плана истории» ${ }^{16}$.

Автор «Слова о законе и благодати» обозначил то, что затем стало буквально ментальным компонентом всей восточнославянской культуры и что следует учитывать в интерпретации ее художественных образцов: фактически, он, прежде всего, настойчиво акцентировал историческую значимость мистической благодати («И благодать Христова, объяв всю землю, её покрыла, подобно водам моря»), которая шире закона, покрывает его собою, позволяет интуитивно правильно действовать в соответствии с самим законом, а не с его «буквой»: «Прежде был дан закон, а потом - благодать, прежде - тень, а потом - истина. Прообраз закона и благодати Агарь и Сарра, рабыня Агарь и свободная Сарра: прежде - рабыня, а потом - свободная (Бъм. 25,11-23; Гал. 4,22-31), - да разумеет читаюший (Мф. 24,15)».

Здесь со всей очевидностью возникает та самая точка бифуркации, вырисовывается контур той несомненной двойственности (между потаенным и очевидным): «Неведомое и тайное премудрости Божией (Пс. 50,8) сокрыто было от ангелов и от людей не как бы не являемое нечто, но утаенное и должное открыться в кончину век $а »$. Под тем или иным обозначением имманентная двойственность в дальнейшем будет присутствовать в лучших русских художественных текстах культуры, начиная от церковных сооружений и икон, которые можно интерпретировать как специфическую (знаковую) версию повествовательного эпического текста. $\mathrm{B}$ «Слове» Иллариона двойственность иконично обозначена конструктивным параллелизмом прочтения двух библейских ситуаций: «И сказала Сарра Аврааму: вот, предназначил мне Господь Бог не рождать; войдиже к служанке моей Агари и будешъ иметь детей от неё (Быт. 16,2) - А благодать сказала Богу: если не пришло ешё время сойти мне на землю и спасти мир, сойди на гору Синай и утверди закон.

И внял Авраам речам Сарринъм, и вошёл к служанке ёе Агари (Бът. 16,2.4). - Внял же и Бог словесам благодати и сошёл на Синай (Исх. 19,16-20)».

Реальность этих знаковых библейских событий, отождествление парадигм «закон» и «рабство», в данном случае провозглашается автором лишь «тенью истины»: «И родила Агарь-рабыня от Авраама: рабыня - сына рабыни; и нарек Авра ам имя ему Измаил (Быт. 16,15). - Принёс же и Моисей с Синайской горы закон, а не благодать, тень, а не истину (Исх. 32,15-16; 34,29)».

15 SENDEROVICH, S.: Slovo o zakone i blagodati kak jekzegeticheskij tekst. Ilarion Kievskij i pavlianskaja teologija. Trudy Otdela drevnerusskoj literatury 51, 1999, s. 57.

16 Ibidem. 
Только с таким событием, как зачатие и рождение Христа, «когда посетил Бог человеческое естество, открылось уже неведомое и утаенное и родилась благодать - истина, а не закон, сын, а не раб».

Итак, за несколько десятилетий до «Повести временных лет», предшествуя труду Нестора-летописца, закономерно зарождается и вызревает доминантная идея всей последующей русской мировоззренческой традиции - о двойственности человеческого естества, основанная также на апостольских словах о «сокровенном сердиа человеке в нетленной [красоте] кроткого и молчаливого духа, ито драгоценно пред Богом» (1 Петра, 3:4). Прокомментированные митрополитом Иларионом образы Агари и Сарры, как двух символических парадигм Запада и Востока, можно полагать по-прежнему функциональным ключом к ситуации хронического противостояния и взаимонепонимания западноевропейской и восточноевропейской культур.

В отличие от мировоззренческого рационализма Запада, весьма длительное время жизнь русского общества была вероцентричной в прямом смысле: с церковыю и ее мистическим телом было связано все существование человека. «Кодирование истории», непременная идентификация событий и фактов, т.е. смена историографической парадигмы по западному образцу начинается под воздействием радикализма Петровских реформ, но сама культура и художественная литература в целом продолжали и, может быть, продолжают до сих пор сохранять прежний апперцептивный фоновый режим, при котором человек одновременно живет как в историческом времени, таки вне его. Правда, так наз. идеологическая составляющая уже может быть иным, значительно модернизированным мировоззренческим стержнем, что выразится и в писательстве.

Рассматривая «разноголосицу» и «разноречие» в русском романе, на конкретном примере Льва Толстого, именно М. Бахтин обращает наше внимание на наличие «апперцептивного фона», его латентную значимость для понимания сказанного автором. В данном случае он интерпретирует ситуацию через категорию диалога: «Так, слово у Толстого отличается резкой внутренней диалогичностью, причем оно диалогизовано как в предмете, так и в кругозоре читателя, смысловые и экспрессивные особенности которого Толстой остро ощущает. Эти две линии диалогизаиии (в большинстве случаев полемически окрашенной) очень тесно сплетены в его стиле: слово y Толстого даже в самых «лирических» выражениях и в самых «эпических» описаниях созвучит и диссонирует (больше диссонирует) с различными моментами разноречивого соииально-словесного сознания, опутьвающего предмет, и в то же время полемически вторгается в предметный и ченностный кругозор читателя, стремясь поразить и разрушить аппериептивный фон его активного понимания» ${ }^{17}$.

Правда, Бахтин не связывает позицию романиста, как бы нам этого ни хотелось, с собственно исконной отечественной традицией, а утверждает, что

17 BAHTIN, M. M.: Voprosy literatury i jestetiki: Issledovanija raznyh let. Moskva: Hudozhestvennaja literatura, 1975 , s. 76. 
«в этом отношении Толстой - наследник ХVIII века, в особенности Руссо. Отсюда, - как пишет ученый, - иногда происходит сужение того разноречивого сочиального сознания, с которым полемизирует Толстой, до сознания ближайшего современника, современника дня, а не эпохи, и вследствие этого и крайняя конкретизачия диалогичности (почти всегда полемики)» ${ }^{18}$. Для нас остается значимым замечанием указание на разноречивость социального сознания, а также на перспективу сужения в диалоге мировоззренческого кругозора с языка эпохи в язык дня.

Наконец, какое состояние искусства следует считать оправданным с точки зрения его историографической составляющей? Несомненно, то, которое возникает в контексте события, поскольку оно имеет основное преимущество - соприсутствие в историческом времени. При этом историографические акценты могут быть выражены в производных текстах самыми разнообразными средствами, к примеру, через жанр, соответствующую времени и его идеям атрибутику, молодежный сленг, определенные технические возможности и пр.

Творчество любого из классиков, особенно XIX ст., в этой призме обнаружит специфическую палитру. Выразительным примером является Федор Достоевский. Однако бросается в глаза, что в жанровом опыте этого писателя никак не представлен исторический роман. У читателя может сложиться убеждение, что его герои вообще существуют вне истории, практически никак с нею не соотносятся. Исключения редки и потому заметны. Например, то, что мы читаем в эпилоге романа «Идиот» (1868) об экзальтированной барышне Аглае Епанчиной в связи со «странной» на первый взгляд биографической развязкой ее вхождения в польский католический мир, взамен недавнего страстного увлечения князем Мышкиным и его православными идеями ${ }^{19}$. В контексте своего исторического времени, охваченного идеей европеизма, подобную фабулу нельзя назвать прецедентной. По формуле Ю. Кудрявцева, «Европеизм, по Достоевскому, - это совокупность буржуазности, католичизма, либерализма и нигилизма. Именно эти явления как чисто европейские и противопоставляются явлениям российским» ${ }^{20}$. Однако, знаменательно, что автор, объективируя свое мнение, делегирует его литературному персонажу, представив истолкование этого эпизода всего лишь как реплику из частной переписки: «Пленил он Аәлаю необъчайньмм благородством своей истерзавшейся страданиями по отчизне души, и до того пленил, ито та, еще до выхода замуж, стала членом какого-то заграничного комитета по восстановлению Польши и сверх того попала в католическую исповедальню какого-то знаменитого патера, овладевшего ее умом до исступления...» ${ }^{21}$. В совсем небольшом заключительном фрагменте сюжетной ветки мы видим героиню втягивающейся в какое-то чуждое, но исторически реальное русло и, безусловно, здесь затронут нерв русско-польского вопроса, однако ничего более того не сказано.

18 Ibidem.

19 DOSTOEVSKiJ, F. M.: Polnoe sobranie sochinenij v 30 tomah. Leningrad: Nauka, 1973, t. 8, s. 509.

20 KUDRJAVCEV, Ju. G.: Tri kruga Dostoevskogo (Sobytijnoe. Social'noe. Filosofskoe). Moskva: Izd-vo Moskovskogo universiteta, 1979, s. 84.

21 DOSTOEVSKIJ, F. M.: Polnoe sobranie sochinenij v 30 tomah. Leningrad: Nauka, 1973, t. 8, s. 509. 
В стиле Достоевского как романиста предпочтение, по-видимому, отдавалось художественным обобщениям, рассчитанным на понимающего читателя. Однако в контексте всего романа такая развязка требует серьезного рецептивного решения.

На этом заострял наше внимание и богослов ХХ ст. прп. Иустин (Попович): «Проблема Европь есть проблема католицизма - таков вывод, к которому пришел Достоевский, изучая Европу. <...> Впервые к этой проблеме Достоевский основательно обрашается в своем романе «Идиот» (1868). И в качестве носителя своей идеи берет люби мого князя Мыикина» ${ }^{22}$. Отсюда, поступок Аглаи должен быть прочитан в ключе противопоставления этих двух персонажей, а отнюдь не как «странный».

Отношение русского классика к своему историческому времени было более чем внимательным, о чем убедительно свидетельствует им написанное - и художественные тексты, и широкая переписка, и публицистика «Дневника писателя». Особую функцию исторического факта в жанре «Дневника писателя» некогда обозначил П. В. Палиевский: «Он видит их художественную возможность уже в том, «что они факты» - какое-то особое писательство, отчасти фантастическое, наступление художественного смъсла изнутри самого материала» ${ }^{23}$.

«Дневник писателя» создавался Достоевским с двумя перерывами - в 1873, 1876-77 гг. и в 1880-1881 гг., и, таким образом, его должно относить к периоду подведения мировоззренческих итогов. «Разные проглянувшие между газетных строк характерь, хроника суда, истории со слов очевидиа - все идет в дело для этой книги. "Дневник” наполняется от них каким-то проходным, но непреходяшим смыслом и становится произведением, далеко обогнавшим свое время», - характеризует текст все тот же исследователь ${ }^{24}$. Одним из первых в советском литературоведении о жанровой природе «ДП» размышлял Г. Д. Гачев. Он подчеркнул сознательную «анти-интимностъ» текста, значимость проблематики и ряд других неоспоримых признаков уникальности представленного Достоевским жанра и определил его как «анти-денвник» ${ }^{25}$. Действительно, перед нами дневник событий вовсе не личной жизни, а жизни европейской. Налицо имплицитация авторского сознания в исторический текст эпохи.

Следует подчеркнуть, что писательский дар $\Phi$. Достоевского не случайно воспринимался в большинстве случаев, начиная с оценки В. Соловьева, как пророческий, что провоцировало сильную поляризацию мнений между западническим и славянофильским ответвлениями русского общественного сознания. Сказанное писателем всегда воспринималось как чрезвычайно веское слово, но - исходя из того концепта истории, которого придерживались его оппоненты. Наиболее характерные в этом смысле оценки его исторических взглядов и про-

22 IUSTIN (POPOVICH), prepodobnyj: Filosofija i religija F. M. Dostoevskogo. Minsk: Izdatel' D. V. Harchenko, 2007, s. 251.

23 PALIEVSKIJ, P. V.: Literatura i teorija. Moskva: Sovetskaja Rossija, 1979, s. 132.

24 PALIEVSKIJ, P. V.: Literatura i teorija. Moskva: Sovetskaja Rossija, 1979, s. 133.

25 Доклад «Дневник писателя» Ф. Достоевского как анти-дневник», прочитанный на конференции по теории литературы в МГУ (декабрь, 1985 г.). 
гнозов высказывались последовательно в 1906, 1921 и 1947 гг. Горячая и отрицательная принадлежала Льву Шестову (1906), взвешенные - Питириму Сорокину (1921) и Константину Мочульскому (1947).

Шестов возмущался тем, что «очень многие смотрели на Достоевского как на человека, пред которым лежали открытыми книги человеческих судеб. И это не только после его смерти, но даже еще и при жизни» ${ }^{26}$, тогда как, - по его мнению, - «Люди приняли придворного певча существующего порядка за вдохновителя дум, за властителя отдаленнейших судеб России» ${ }^{27}$. Навряд ли оправдана и следующая едкая реплика Шестова: «России опять придется учиться у Запада, как уже не раз приходилось Учиться... И Достоевский гораздо лучше сделал бы, если бы не пытался пророчествовать. <...> Пророками бывают Бисмарки, они же и канилерами бывают, т.е. первыми в деревне, первыми в Риме... Достоевскому же суждено вечное «накануне»?!» ${ }^{28}$. Заметим, все это было сказано Шестовым в адрес писателя до Октябрьского переворота 1917-18 гг., который сам по себе опроверг иронию философа.

Однако, именно эта оценка была подхвачена и советскими комментаторами-историками. Например, толкуя отношение российской общественности к Балканской проблеме в свете трех основных направлений общественного движения той поры - демократического, либерального и консервативного (справедливо подчеркивалось, что представители последнего «отнюдь не были единъ во всех свочх помыслах»), В. Я. Гросул отнес классика к реакционному кругу людей, который собирался вокруг наследника престола - будущего императора Александра III, наиболее видными идеологами которого считались В. Победоносцев и М. Катков. Это направление, по словам историка, «стремилось использовать балканские события для отвлечения народа от внутренних сочиалъных проблем» ${ }^{29}$. В своем историческом обзоре ученый счел необходимым подчеркнуть, что, «именно к этим слоям русского общества примкнул выдаюшийся русский писатель Ф. Достоевcкuй» ${ }^{30}$.

Между прочим, поставленный Шестовым в сравнение Достоевскому германский рейхсканцлер у самого писателя вызывал исключительно негативную реакцию, в кругу близких людей он не раз называл его глупцом ${ }^{31}$. Особенно

26 SHESTOV, Lev: Prorocheskij dar. In: O Dostoevskom: Tvorchestvo Dostoevskogo v russkoj mysli 1881-1931 godov. Moskva: Kniga, 1990, s. 119.

27 SHESTOV, Lev: Prorocheskij dar. In: O Dostoevskom: Tvorchestvo Dostoevskogo v russkoj mysli 1881-1931 godov. Moskva: Kniga, 1990, s. 121-122.

28 SHESTOV, Lev: Prorocheskij dar. In: O Dostoevskom: Tvorchestvo Dostoevskogo v russkoj mysli 1881-1931 godov. Moskva: Kniga, 1990, s. 127.

29 GROSUL, V. Ja.: Vostochnyj krizis 70-h godov XIX v. i rossijskoe obshhestvo. In: 100 let osvobozhdenija Balkanskih narodov ot Osmanskogo iga: Materialy mezhdunarodnoj konferencii. Moskva, 15-17 maja 1978. Moskva: Nauka, 1979, s. 136.

30 Ibidem.

31 Запись в дневнике С. И. Смирновой (Сазоновой) от 1 марта 1880: «Достоевский называет Бисмарка глупцом». - См.: GROSUL, V. Ja.: Vostochnyj krizis 70-h godov XIX v. i rossijskoe obshhestvo. In: 100 let osvobozhdenija Balkanskih narodov ot Osmanskogo iga: Materialy mezhdunarodnoj konferencii. Moskva, 15-17 maja 1978. Moskva: Nauka, 1979, s. 276. 
в разных контекстах Бисмарк упоминается в романе «Подросток» (1875), хотя его характеристики звучат не в авторской речи. Наиболее зримый пример отсюда (размышления юного Аркадия Долгорукого): «...идеи пошлье, скорые - понимаются необъкновенно быстро, и непременно толпой, непременно всей уличей; мало того, считаются величайшими и гениальнейшими, но - лишь в денъ своего появления. Дешевое не прочно. Бъстрое понимание - лишь признак пошлости понимаемого. Идея Бисмарка стала вмиг гениальною, а сам Бисмарк - гением; но именно подозрительна эта быстрота: я жду Бисмарка через десять лет, и увидим тогда, ито останется от его идеи, а может быть, и от самого канилера» ${ }^{32}$. Как известно, большое место занимал Бисмарк именно в публицистике Достоевского, и, по принятому академической наукой мнению, писатель «настороженно следил за политической деятельностью Бисмарка, общее отношение к ней было весьма отрииательным» ${ }^{33}$. Следует также отметить, что и помимо Бисмарка все значимые персонажи европейской истории того времени не остались без его комментария.

Наконец, уже вскоре после событий Октябрьского переворота прозвучало совершенно противоположное мнение о значении историографизма Достоевского, высказанное Питиримом Сорокиным: «Гениальный твореи «Братьев Карамазовых» и в своих художественных произведениях, и в своем “Дневнике писателя" постоянно касался самых главных, самых трудных общественных вопросов и способов $u x$ решения» ${ }^{34}$. Целостность исторического мировосприятия позже отметит и К. Мочульский: «Двухлетняя работа над “Дневником» завершается той религиозно-философской идеей, которая рождает из себя замысел романа «Братья Карамазо$B b \iota \gg \gg{ }^{35}$.

В 1921 г. П. Сорокин, как известно, впоследствии авторитетнейший социолог и культуролог, подчеркнул справедливость замечания Достоевского об обозначившемся еще во времена писателя классовом противоборстве: «та и другая стороны (буржуазия и пролетариат) страшно не правы, и та, и другая погибнут во грехах своих... Единственно возможное решение вопроса - есть постановка нравственная, т.е. христианскал. Рано ли, поздно ли, после рек крови и ста миллионов голов должнь будут признать ее, ибо в ней только одной и исход» или “Вместо вина упъются кровъю» 36 .

Цитируя Достоевского, ученый акцентировал справедливость его прогноза: «Напишите какие угодно конститучии, пересадите какие угодно учреждения, но раз люди безнравственны, раз в них и их поступках нет нравственной идеи любви, то ника кого улучшения быть не может. "Что толку поставить учреждение и написать на нем: Liberté, Egalité, Fraternité» (свобода, равенство, братство)? Ровно никакого толку, так что придется - необходимо, неминуемо придется - присоединить к трем словечкам чет-

32 DOSTOEVSKIJ, F. M.: Polnoe sobranie sochinenij v 30 tomah. Leningrad: Nauka, 1975, t. 13, s. 77.

33 DOSTOEVSKIJ, F. M.: Polnoe sobranie sochinenij v 30 tomah. Leningrad: Nauka, 1986, t. 29, kn. 2 , s. 329.

34 SOROKIN, Pitirim: Zavety Dostoevskogo. In: O Dostoevskom: Tvorchestvo Dostoevskogo v russkoj mysli 1881-1931 godov. Moskva: Kniga, 1990, s. 246.

35 MOCHUL'SKIJ, K. V.: Gogol'. Solov'ev. Dostoevskij. Moskva: Respublika, 1995, s. 504.

36 SOROKIN, Pitirim: Zavety Dostoevskogo. In: O Dostoevskom: Tvorchestvo Dostoevskogo v russkoj mysli 1881-1931 godov. Moskva: Kniga, 1990, s. 249. 
вертое: «ои la mort» (или смерть), «fraternité ou la mort» (братство или смерть) - и пойдут братья откалывать головы братьям, чтобы получить через насилие и «гражданское учреждение» братство. Не будет в этом случае ни свободъ, ни равенства. Вместо свободъ получается только «у богатьх уединение и духовное самоубийство, а у бедных - зависть и убийство». Вместо равенства иарство эксплуатаиии, угнетения, ненависти и злобы; вместо братства - взаимное поедание. _.. >B этом случае неизбежно «наступит нечто такое, чего никто и не мыслит. Все эти парламентаризмы, все гражданские теории, богатства и банки - все это рухнет в один миг и бесследно. Все это «близко, при дверях». Вы смеетесь? Блаженны смеюшиесл!» ${ }^{37}$.

Перекликается с выводами Сорокина и комментарий К. Мочульского на «идеологические построения» Достоевского, высказанные в 1877 г. По ремарке исследователя, «в тоне проповеди и пророчества»: «Европуждут огромные перевороты, такие, что ум людей отказывается верить в них, считая осуществление их как-бы чем-то фантастическим... Сочиальная револючия и новый сочиальный период в Европе несомненнъ». С новой силой проповедует он свое мистическое народничество. "В наше время пророческие прозрения Достоевского сбываются: «колоссальное и стихийное» уже охватило весь старый мир» (подчеркнуто автором. - О. Ч.) $)^{38}$.

Между столь разными мнениями об историческом чутье Достоевского лежит убедительный опыт двух мировых войн, краха империй, колониальных систем и перекраивания европейских границ, подтвердивший справедливость предчувствий писателя.

Как бы ни акцентировалась идея художественной исключительности его творчества, все же случай $\Phi$. М. Достоевского как писателя-историографа, продолжавшего органичную стратегию русской художественной мысли (двойственность мировосприятия в аспекте мистики и факта), особо выразился в его публицистике, поскольку в «Дневнике писателя» он выступил не только свидетелем и комментатором текущего момента истории, но и прозорливым аналитиком. Вопрос о том, откуда черпал информацию Достоевский, прост: газетная и журнальная периодика, личные встречи. В специфическом для Запада истолковании автора нашли отражение важные политические реалии и исторические имена эпохи ${ }^{39}$.

Итак, вывод из сказанного: независимо от внутренней установки самого художника значимым свойством его творческих достижений остается в нужный момент свидетельствовать о времени, исходя из мировоззренческих установок сформировавшейся традиции. Аналитикам национальных литературных процессов важно понимать историческую предысторию, прочитывать отсюда исходящую мотивацию всякого авторского труда и иметь телеологическую установку на ее рецепцию в перспективе своего собственного исторического момента.

37 SOROKIN, Pitirim: Zavety Dostoevskogo. In: O Dostoevskom: Tvorchestvo Dostoevskogo v russkoj mysli 1881-1931 godov. Moskva: Kniga, 1990, s. 249-250.

38 MOCHUL'SKIJ, K. V.: Gogol'. Solov'ev. Dostoevskij. Moskva: Respublika, 1995, s. 503.

39 См. CHERVINSKAJA, O. V.: Pisatel' kak istoriograf: serbskij vopros i lichnost' generala M. G. Chernjaeva v recepcii F. M. Dostoevskogo (neprochitannaja stranica «Dnevnika pisatelja»). Istoryčna panorama 10, 2010, s. 41-66. 


\section{Литература}

BAHTIN, M. M.: Voprosy literatury i jestetiki: Issledovanija raznyh let. Moskva: Hudozhestvennaja literatura, 1975.

CHERVINSKAJA, O. V.: Pisatel'kak istoriograf: serbskij vopros i lichnost'generala M. G. Chernjaeva v recepcii F. M. Dostoevskogo (neprochitannaja stranica «Dnevnika pisatelja»). Istoryčna panorama 10, 2010, s. 41-66.

DOSTOEVSKIJ, F. M.: Polnoe sobranie sochinenij v 30 tomah. Leningrad: Nauka, 1972-1990.

FISANOV, V. P.: Prohrane supernyctvo (SŠA ta Avstro-Uhorščyna u Central'nijJevropi v roky Peršoji svitovoji vijny). Černivci: Zoloti lytavry, 1999.

GORSKIJ, A. A.: Problemy izuchenija «Slova o pogibeli Ruskyja zemli» (K 750-letiju so vremeni napisanija). Trudy Otdela drevnerusskoj literatury 43, 1990, s. 18-38.

GROSUL, V. Ja.: Vostochnyj krizis 70-h godov XIX v. i rossijskoe obshhestvo. In: 100 let osvobozhdenija Balkanskih narodov ot Osmanskogo iga: Materialy mezhdunarodnoj konferencii. Moskva, 1517 maja 1978. Moskva: Nauka, 1979, s. 134-145.

IUSTIN (POPOVICH), prepodobnyj: Filosofija i religija F. M. Dostoevskogo. Minsk: Izdatel' D. V. Harchenko, 2007.

KUDRJAVCEV, Ju. G.: Tri kruga Dostoevskogo (Sobytijnoe. Social'noe. Filosofskoe). Moskva: Izd-vo Moskovskogo universiteta, 1979.

Lavrent'evskaja letopis'. Moskva: Izd-vo AN SSSR, 1962.

MOCHUL'SKIJ, K. V.: Gogol'. Solov'ev. Dostoevskij. Moskva: Respublika, 1995.

MOLDOVAN, A. M.: «Slovo o zakone i blagodati» Ilariona. Kiev: Naukova dumka, 1984.

MOSTOVSKAJA, N. N.: Dostoevskij v dnevnikah S. I. Smirnovoj (Sazonovoj). In: Dostoevskij: Materialy i issledovanija. Leningrad: Nauka, 1980, t. 4, s. 271-278.

PALIEVSKIJ, P. V.: Literatura i teorija. Moskva: Sovetskaja Rossija, 1979.

SENDEROVICH, S.: Slovo o zakone i blagodati kak jekzegeticheskij tekst. Ilarion Kievskij i pavlianskaja teologija. Trudy Otdela drevnerusskoj literatury 51, 1999, s. 43-57.

SHESTOV, Lev: Prorocheskij dar. In: O Dostoevskom: Tvorchestvo Dostoevskogo v russkoj mysli 1881-1931 godov. Moskva: Kniga, 1990, s. 119-127.

Slovo o pogibeli Russkoj zemli. Moskva: Nauka, 2005.

SOLOV'EV, A. V.: Zametki k «Slovu o pogibeli Ruskyja zemli». Trudy Otdela drevnerusskoj literatury 15, 1958, s. 78-115.

SOROKIN, Pitirim: Zavety Dostoevskogo. In: O Dostoevskom: Tvorchestvo Dostoevskogo v russkoj mysli 1881-1931 godov. Moskva: Kniga, 1990, s. 246-254.

UZHANKOV, A. N.: «Slovo o Zakone $i$ Blagodati» $i$ drugie tvorenija mitropolita Ilariona Kievskogo. Moskva: Akademika, 2013.

\section{Ольга Вячеславовна Червинская, доктор филологических наук, профессор}

Заведующая кафедрой зарубежной литературы и теории литературы

Черновицкий национальный университет имени Юрия Федьковича

Черновцы, Украина

o.chervinska@chnu.edu.ua 